\title{
What should be the ideal time interval between repeated extracorporeal shock wave lithotripsy sessions for renal stone treatment?
}

\author{
Senol Adanur · Tevfik Ziypak · Turgut Yapanoglu • \\ Ozkan Polat
}

Received: 11 June 2014 / Accepted: 30 June 2014 / Published online: 17 July 2014

(C) Springer-Verlag Berlin Heidelberg 2014

\section{Dear sir,}

We have read the article by Schnabel et al. [1] with great interest. The authors aimed to determine the incidence of and risk factors for renal hematoma (RHT) after extracorporeal shock wave lithotripsy (SWL). We are sure that this prospective designed study encompassing 857 renal stone patients who had been treated with 1,300 sessions of SWL therapy will make great contributions to the literature.

The authors reported that RHT developed after SWL therapy in four asymptomatic, and three symptomatic patients (total $n=7 ; 0.53 \%$ ) who were treated with surgical $(n=1)$ and conservative $(n=6)$ therapy. They have demonstrated advanced age, and vascular comorbidities as risk factors for the development of RHT.

The authors also reported application of three sessions of SWL within 7 days for two patients in whom RHT developed. Although in the European Association of Urology (EAU) guidelines has not been reached a consensus about the required time intervals between repeated SWL sessions applied for renal stones [2], we think that extremely shorter time intervals between repeated SWL sessions applied for the management of renal stones of these two patients increased the incidence of RHT in their study .

In the literature, severe renal damage developed after SWL has been related to a hemorrhagic event. Rates of renal hematomas range between $\leq 1$, and $20 \%$ depending on the type of the lithotriptor used, radiological imaging modality, and duration of the follow-up period. Significantly higher, and alarming rates of renal hematoma $(3-12 \%)$ have been reported with the use of new generation lithotriptors. The severity of renal hematoma related to SWL, can range between localized, mild contusion of the renal parenchyma, and severe bleeding from a large hematoma which might require blood transfusion and rarely angioembolization. Some hematomas can persist for a few months or years, most of them regress within weeks without resultant sequalae [3]. In the light of this information in the literature, if one thinks that a renal contusion generally improves within at least 1 or 2 weeks, we conceive that a time interval of at least 1 week between two SWL sessions might preclude potentially unwanted complications.

In conclusion, this continual uncertainty has reminded us once more that precise answers should be provided in the guidelines to the question 'What should be the ideal time interval between SWL sessions in the treatment of renal stone patients?

Conflict of interest The authors declare that there is no conflict of interest.

\section{References}

1. Schnabel MJ, Gierth M, Chaussy CG, Dötzer K, Burger M, Fritsche HM (2014) Incidence and risk factors of renal hematoma: a prospective study of $1,300 \mathrm{SWL}$ treatments. Urolithiasis 42(3):247-253. doi:10.1007/s00240-014-0637-4

2. Turk C, Knoll T, Petrik A, Sarica K, Skolarikos A, Straub M, Seitz C (2014) The EAU guidelines on urolithiasis, pp 1-98

3. Matlaga BR, Lingeman JE (2012) Surgical management of upper urinary tract calculi. In: Wein AJ, Kavoussi LR, Novick AC, Partin AW, Peters CA (eds) Campbell-walsh urology, 10th edn. Saunders Elsevier, Philadelphia, pp 1357-1410 